NBER WORKING PAPER SERIES

\title{
MAKE VERSUS BUY IN TRUCKING: ASSET OWNERSHIP, JOB DESIGN AND INFORMATION
}

\author{
George P. Baker \\ Thomas N. Hubbard \\ Working Paper 8727 \\ http://www.nber.org/papers/w8727 \\ NATIONAL BUREAU OF ECONOMIC RESEARCH \\ 1050 Massachusetts Avenue \\ Cambridge, MA 02138 \\ January 2002
}

We would like to thank all those we talked to at trucking firms and private fleets for allowing us to visit their firms and discuss the issues we investigate in this paper. Thanks to Ann Merchant for research assistance and Oliver Hart, Bengt Holmstrom, Paul Milgrom, Canice Prendergast, Preston McAfee, and many seminar participants for comments. We gratefully acknowledge support from NSF grant SES-9975413, the NBER/Sloan Pin Factory Project, and the Harvard Business School Division of Research. The views expressed herein are those of the authors and not necessarily those of the National Bureau of Economic Research.

(C) 2002 by George P. Baker and Thomas N. Hubbard. All rights reserved. Short sections of text, not to exceed two paragraphs, may be quoted without explicit permission provided that full credit, including (C) notice, is given to the source. 
Make Versus Buy in Trucking: Asset Ownership, Job Design and Information George P. Baker and Thomas N. Hubbard

NBER Working Paper No. 8727

January 2002

JEL No. D23, L22, L92

\section{ABSTRACT}

Explaining patterns of asset ownership in the economy is a central goal of both organizational economics and industrial organization. We develop a model of asset ownership in trucking, which we test by examining how the adoption of different classes of on-board computers (OBCs) between 1987 and 1997 influenced whether shippers use their own trucks for hauls or contract with for-hire carriers. We find that OBCs' incentive-improving features pushed hauls toward private carriage, but their resource-allocation-improving features pushed them toward for-hire carriage. We conclude that ownership patterns in trucking reflect the importance of both incomplete contracts (Grossman and Hart (1986)) and of job design and measurement issues (Holmstrom and Milgrom (1994)).

George P. Baker

Graduate School of Business

Harvard University

Baker West 283

Boston, MA 02163

and NBER

gbaker@hbs.edu
Thomas N. Hubbard Graduate School of Business University of Chicago 1101 East 58th Street Chicago, IL 60637 and NBER thomas.hubbard@gsb.uchicago.edu 


\section{Introduction}

Understanding the patterns of asset ownership in the economy is a central goal of both organizational economics and industrial organization because it provides insights on firm boundaries and industry structure. Major progress towards this goal was provided by Grossman and Hart's seminal paper in 1986, which argues that asset ownership confers on owners residual rights of control that give them power and thus incentives to devote effort to value-increasing activities. In this view, firms' boundaries are determined by the optimal allocation of these residual rights of control. Holmstrom and Milgrom (1994), however, argue that firms' boundaries reflect trade-offs in which asset ownership interacts with job design and other organizational decisions. If so, firms' boundaries may reflect factors that do not appear in Grossman and Hart's (1986) theory, including those that affect the optimal allocation of tasks across individuals. In 1999, Holmstrom offered a critique of the property rights view in which he argues that it fails to explain why firms rather than individuals own assets. He extends the insight from the 1994 paper to argue that firms own assets precisely because this mutes the incentives that come with individual asset ownership, allowing the firm to operate as a "subeconomy" that can more precisely balance incentives and implement more complex multitask job designs.

In this paper, we argue that the pattern of asset ownership in trucking - in particular the decision by shippers about whether to use their internal fleet of trucks for a haul or contract with for-hire carriers - reflects not only the factors identified in Grossman and Hart's theory, but also those highlighted in Holmstrom and Milgrom (1994). Consistent with the former, ownership patterns reflect trade-offs that arise from providing intermediaries strong incentives to identify profitable uses for trucks. Consistent with the latter, ownership patterns also reflect issues of job design: i.e., the degree to which drivers simply drive trucks, or provide a more complex combination of transportation and service. Job design matters because "service-intensive" trucking hinders intermediaries' ability to find profitable uses for the truck. Shipper ownership

of trucks mutes incentives and favors service-intensive trucking in which drivers' jobs involve more than just driving trucks. 
We develop a model that combines these theoretical insights. The model generates two sets of comparative static predictions. One set of predictions, including that service-intensive trucking is performed by private fleets, is consistent with well-known cross-sectional patterns in the industry. The other set of predictions concerns how changes in the informational environment affect ownership. We test this second set of predictions using data from the 1987, 1992, and 1997 Truck Inventory and Use Surveys, which contain detailed truck-level information about trucks' characteristics, ownership, and use. In particular, we test predictions on how the diffusion of different types of on-board computers (OBCs) during the late 1980s and early 1990s alters the "make versus buy" decision for shippers. We predict that the adoption of certain types of OBCs should lead indirectly to more shipper ownership of trucks, by lowering the agency costs associated with complex job designs. We predict that the additional capabilities of other types of OBCs - those that provide location information and real-time communication - should lead to less shipper ownership of trucks, because these additional capabilities enhance the comparative advantage of for-hire carriage with respect to truck utilization and dispatch. We find evidence in favor of both of these predictions.

Our results strongly suggest causal links between informational and organizational changes in the trucking industry. They show that ownership patterns in trucking reflect the importance of not only incomplete contracts (as stressed by Grossman and Hart (1986)), but also of job design and measurement issues (like those stressed in Holmstrom and Milgrom (1994)). These findings thus shed important light on theories of organizations. They also make a contribution to the long-running debate about how information technology (IT) diffusion affects the boundaries of the firm. ${ }^{1}$ We note that information technology in general provides at least two capabilities - improved monitoring of agents and improved coordination of activities - and that the organizational impact of these capabilities can differ (Jensen and Meckling, 1992). In trucking, improvements in monitoring (and the attendant improvement in incentives) lead to larger, more integrated firms, while improvements in coordination (resulting in better asset

\footnotetext{
${ }^{1}$ Leavitt and Whisler (1958), Malone, Yates, and Benjamin (1987), Brynjolfsson and Hitt (1997).
} 
utilization) lead to more diffuse asset ownership and smaller, less integrated firms. Whether these results generalize to other settings remains an open question.

In this paper we do not consider a third possibility regarding truck ownership: drivers may own trucks. We investigate driver ownership of trucks in detail in another paper (Baker and Hubbard (2000)). In that paper, we propose that asset ownership strengthens drivers' incentives to drive in ways that preserve trucks' value, but also encourages them to engage in rent-seeking behavior. We then argue that $\mathrm{OBC}$ adoption alters this trade-off by allowing companies (either for-hire carriers or private fleets) to use the monitoring capabilities of OBCs to substitute for asset ownership. We show that OBCs lead to less driver ownership of trucks, especially for hauls where rent-seeking is a potential problem. We ignore these issues in the present paper because we believe they are not salient to the make-or-buy decision. Situations that are on the margin between for-hire carriage and private carriage are not those where owner-operators are used. In general, owner-operators are used for hauls that require little if any service provision by the driver, and for good reason. The multitasking problems with service provision that lead for-hire carriage to be inefficient relative to private carriage are exacerbated when drivers control trucks. This is borne out by the fact that when shippers outsource hauls with non-negligible service requirements, they rarely, if ever, do so by contracting with owner-operators. ${ }^{2}$

The paper is organized as follows. In the next section, we describe the institutional setting that we model, defining the players, describing their roles in the provision of trucking services, and characterizing the contracting environment in which they operate. In Section 3, we present our model of job design and asset ownership. Section 4 describes OBCs and generates our main empirical propositions. In Section 5, we describe our data and present the main empirical patterns. Section 6 contains our main empirical results regarding the relationships between OBC adoption and organizational change. Section 7 concludes.

\footnotetext{
${ }^{2}$ In our empirical tests, "for-hire carriage" includes driver- and carrier-owned trucks, ownership structures where shippers do not own trucks. Our results are unchanged when we leave out owner-operators altogether.
} 


\section{Job Design, Search Incentives, and Asset Ownership in Trucking}

This section describes the institutional framework, drawing heavily from what we learned in a series of site visits and interviews. We describe the basic trade-offs involved in job design and asset ownership decisions and explain why these decisions might be related. Throughout the section, we will refer to several different parties. Drivers are individuals who drive trucks and may have other customer service oriented tasks. Shippers are firms or divisions with demands to move cargo from one place to another. Carriers are firms or divisions that supply transportation services. Carriers that supply services using trucks owned by shippers are private carriers (i.e., shippers' internal fleets). Carriers that supply services using trucks they own themselves are forhire carriers. Brokers are third party informational intermediaries.

\section{Driver Job Design: Driving and Service Provision}

Drivers can engage in two sorts of activities: driving the truck and performing nondriving service activities. ${ }^{3}$ Defining drivers' jobs to include non-driving activities lets carriers offer high service options in which their customers can ask drivers to do things such as help unload the truck and sort and store the cargo. This gives customers flexibility in how many of their own workers they allocate to such tasks, and can improve the division of labor in the short run because deliveries might take place when the opportunity cost of customers' workers' time is high.

The benefit of giving drivers service responsibilities varies systematically across hauls with the characteristics of the cargo. There are rarely such benefits when they haul bulk goods such as gravel, ores, or grain, in large part because no handling is required upon delivery: when trucks reach their destination, drivers dump the cargo where the recipient wants it. Giving drivers service responsibilities is also generally unproductive when trucks haul goods for which handling requires special equipment. For example, special machines - which drivers generally are either unable or not trusted to use -- are usually necessary to move very heavy goods (large rolls of paper, sheet metal). As a consequence, drivers generally just drive trucks when they haul bulk or unwieldy goods.

\footnotetext{
${ }^{3}$ See Ouellet (1994) for a detailed description of incentives and the organization of work in trucking.
} 
In contrast, giving drivers service responsibilities can be valuable when trucks haul other classes of goods, such as packaged goods or hazardous cargo. Packaged goods can be carried by hand or transported with standard equipment such as hand trucks, conveyor belts, or forklifts. Handling hazardous cargo such as petroleum or chemicals requires certification, which drivers generally must have to haul such cargo legally. Giving drivers service responsibilities diminishes the extent recipients must have certified personnel. As a consequence, drivers often have service responsibilities when trucks haul packaged goods or hazardous cargo.

A drawback to giving drivers additional responsibilities is that agency costs are higher. ${ }^{4}$ Carriers always face the problem of motivating drivers to pick up and deliver goods on time and drive in ways that preserve trucks' value. When drivers' jobs involve service, they also face the problem of motivating drivers to allocate their time efficiently between driving and service.

Motivating drivers to pick up and deliver goods on time is straightforward because it is relatively easy to evaluate drivers' performance in this dimension. The distances traveled and the return time at the end of the run are known. Carriers also normally have good information regarding whether drivers arrive late to intermediate stops - angry customers call them when they do - and have some information about the impact of factors outside of drivers' control, such as traffic and weather conditions. Thus, when drivers' jobs involve only driving from location to location, the main agency problem that remains is inducing them to drive well because this is what remains non-contractible.

Incentive problems are more complicated when drivers' jobs include service activities. As is generally the case in multitasking problems, incentives must attend both to overall effort levels and the allocation of effort across tasks. In this case, the incentive problem created by multitasking is that carriers now must induce drivers to allocate effort between driving and service appropriately. Simple distance and arrival time data provide little indication of the fraction of time drivers spend driving versus doing other things. Some common service

\footnotetext{
${ }^{4}$ Following Jensen and Meckling (1976), agency costs here include both monitoring costs and the "residual loss" attributable to non-optimal decisions.
} 
activities such as cargo-handling are strenuous. ${ }^{5}$ Drivers with service responsibilities have an incentive to misallocate their effort: for example by taking more time handling cargo, then making it up by driving faster between stops. Carriers may respond to this, in the spirit of Holmstrom and Milgrom (1991, 1994) and Baker (1992), by weakening drivers' incentives with respect to other tasks. For example, they balance incentives by de-emphasizing on-time arrivals or allowing more slack in schedules. In general, agency costs are higher when drivers have more responsibilities because of some combination of lower overall effort levels and a worse allocation of effort across tasks.

\section{Market Clearing: Load Matching and Search}

The demand for trucking services and the supply of truck capacity are highly differentiated. Shippers' demands are specific with respect to time, location, and equipment requirements. Likewise, truck capacity is idiosyncratic with respect to its geographic location and the characteristics of the trailer. Capacity utilization in the industry depends crucially on how efficiently supply and demand - trucks and hauls - are matched. Trucks and hauls are matched in a highly decentralized manner in which shippers, carriers, and third-party brokers search for good matches.

The matching problem is particularly difficult in trucking because individual shippers rarely have demands that fill trucks for both legs of a round-trip. For this reason, once carriers receive service orders from shippers, they then search for complementary hauls. When individual shipments are too small to fill a truck, search takes the form of identifying other shippers with similar demands. When demands are unidirectional, search is directed at identifying shippers with demands that would fill the truck for the return trip (the "backhaul").

Dispatchers and brokers play a crucial role in identifying complementary hauls and arranging matches. Dispatchers work for carriers, and seek to match hauls to trucks within their carrier's fleet. Brokers seek to match hauls to trucks owned by other parties. These parties acquire knowledge about city-pair demand in a two-stage process: they make long-run

\footnotetext{
${ }^{5}$ Drivers whose jobs involve taking a fully-loaded trailer and delivering the goods to various destinations handle up to 40,000 pounds of cargo per day. Handling requires hand-lifting when trucks deliver to places without loading
} 
investments in learning general demand patterns (e.g., who the demanders are), then learn detailed "on the spot" information about short-run demands by contacting shippers' traffic managers periodically throughout the day.

Search for complementary hauls in the short run tends to be more refined, and hence productive, the more precisely parties can forecast when trucks will come free. This, in turn, leads to better matches between trucks and hauls: for example, backhauls begin closer to or sooner after "fronthauls" end and trucks arrive to be loaded closer to when shippers want them. Thus, a second drawback to giving drivers service responsibilities on a haul is that service interferes with search for the following haul; trucks' availability is more predictable following low service than high service hauls. ${ }^{6}$

\section{Asset Ownership and Incentives}

Shippers' make-or-buy decision corresponds to whether they use a truck from their internal fleet or an external fleet for a haul. Industry participants distinguish between private and for-hire carriage by who has control rights over the truck. ${ }^{7}$ Below we discuss how and why asset ownership affects incentives.

Ownership rights over trucks matter because contracts are incomplete with respect to trucks' schedules. In particular, shippers and carriers do not write fully-contingent contracts with respect to trucks' schedules because the relevant contingencies are costly to identify ex ante and verify ex post. To see this, consider one class of scheduling decisions: how long a truck should wait at the loading dock to be loaded. A fully-contingent contract would stipulate how long trucks should wait as a function of all relevant states of the world, including especially those factors affecting the benefits of delay and individual trucks' opportunity cost. Many of these

docks - such as most retail outlets.

${ }^{6}$ In interviews, fleet managers and dispatchers indicated to us that forecasting how long deliveries take is much easier when drivers have fewer service responsibilities. They indicated that they could forecast how long a noservice delivery of a truckload of packaged goods would take within a half-hour window, but could only forecast how long a high-service delivery would take within a two to three hour window.

${ }^{7}$ Trucks in private fleets are sometimes leased, are sometimes driven by short-term employees, and sometimes haul other shippers' goods (such as on backhauls). The distinction between private and for-hire carriage thus does not correspond to residual claimancy, the length of labor contracts, or exclusivity of use. 
factors are known only to shippers and/or carriers and are difficult to verify by outsiders. It is thus prohibitively costly to make contracts contingent on them. Schedule-setting is therefore a residual right of control that is, by definition, held by the truck's owner. ${ }^{8}$

The contractual incompleteness surrounding truck scheduling leads to the main consequence of the allocation of ownership rights. In private carriage, shippers own trucks: if they want to alter trucks' schedules in ways that do not violate existing agreements, they can do so. They can unilaterally require that a truck picking up or delivering goods wait, for example. In for-hire carriage, carriers own trucks. If shippers want to change trucks' schedules, they must negotiate this with carriers.

The possibility that schedules will have to be renegotiated leads to familiar sorts of transactions costs in for-hire carriage. Both parties have an incentive to improve their bargaining position, and thus engage in rent-seeking behavior. ${ }^{9}$ For shippers, this takes the form of identifying other carriers who could serve them on short notice; for carriers, this takes the form of identifying other local shippers with similar demands - finding substitute hauls. Exploring back-up plans expends real resources, and is costly. In private carriage, by contrast, disputes may arise between shippers and their private fleets' dispatchers (or shippers and brokers), but identifying other ways to use trucks does not improve dispatchers' or brokers' bargaining position because they cannot threaten to use trucks for other hauls. Neither private fleet dispatchers nor brokers have incentives to identify substitute hauls for rent-seeking purposes.

While rent-seeking tends to be greater under for-hire carriage, truck utilization also tends to be higher. One reason has to do with firms' incentives to obtain market information and search for complementary hauls. Firms can search more effectively for complementary hauls in the short run if they have previously made investments (in the form of customer relationships

\footnotetext{
${ }^{8}$ In practice, it is common for contracts between shippers and carriers to have clauses that penalize shippers when they delay trucks. The penalties, however, are not state-dependent, and thus are set intentionally high to deter shippers from delaying trucks in states of the world where trucks' shadow value is high. Parties realize that renegotiation is likely to be efficient when trucks' shadow value is low, creating a situation that is analytically similar to those where schedules are non-contractible.

${ }^{9}$ Grossman and Hart (1986), Milgrom and Roberts (1990). Baker and Hubbard (2000) argue that this incentive is also central for understanding why truck drivers tend not to own the trucks they operate.
} 
and general knowledge of demand) in particular markets. Shippers, for-hire carriers, and brokers can all potentially make such investments. But because these investments are more valuable to those who are frequently looking for backhauls, individual shippers will tend to only make significant investments on city-pairs where their trucks haul high volumes of goods regularly. On other routes they will invest less, have less information about demand, and therefore search less productively in the short run than for-hire carriers or brokers, who exploit increasing returns by utilizing knowledge across many shippers' hauls. Intermediaries thus have a comparative advantage in finding complementary hauls in many circumstances. This alone need not imply that truck utilization is necessarily lower under private carriage, since shippers could rely on brokers to find hauls. However, brokers have weaker incentives to find particularly good matches, because they do not own trucks and are thus less able to appropriate as large a share of the value that they create. The combination of strong incentives to learn about demand and strong incentives to find good matches for particular trucks leads matches to be better, and thus truck utilization to be higher, under for-hire than private carriage.

Another reason why truck utilization tends to be higher in for-hire carriage is that drivers are generally assigned fewer service responsibilities. Trucks spend more time on the road and, as noted above, load matching is easier when drivers' responsibilities are narrow.

The next section develops a model of asset ownership and job design that captures the institutional features described above and analyzes organizational relationships formally. This model generates comparative static predictions that explain several important cross-sectional patterns in the industry. It also generates predictions regarding how changes in the informational environment should affect the make-or-buy decision. Later in the paper, we take these predictions to the data.

\section{A Model of Asset Ownership and Job Design}

The model combines elements of Holmstrom and Milgrom $(1991,1994)$ and Grossman and Hart (1986). We embed multi-task models of driver job design and dispatcher effort towards finding hauls into a setting in which non-contractible truck scheduling problems make asset ownership important. The timing follows. Initially, a shipper's "fronthaul" and a matching truck 
are assumed to exist: we do not model the process of matching fronthauls to trucks. This haul may be one for which the value of service is high or low. We assume that parties cannot write a complete contract with respect to this haul ex ante. Organizational form is then chosen; at this point, asset ownership and drivers' job design are determined. Next, search for complementary backhauls (and possibly substitute fronthauls) occurs. Depending on asset ownership and the organizational form chosen, either a carrier or a broker chooses how much to search for hauls that complement or substitute for the shipper's haul. Parties then bargain; this determines which haul the truck is used for and how the surplus is split. Finally, production takes place (including provision of service by the driver) and payoffs are realized.

Complementarities between job design and asset ownership are critical to the results, and are a central feature of our model. To highlight this relationship and simplify the exposition, we develop a model first of driver job design, then overlay the shipper's "make-or-buy" decision. When shippers own trucks, this corresponds to "make"; when they do not, this corresponds to "buy." The "make" option has two possible solutions to the problem of matching trucks to hauls: using the shipper's own dispatchers or using brokers. We begin with a model of driver job design.

\section{Driver Job Design: Driving and Service Provision}

Let $\mathrm{s}$ be the scope of the driver's activities, and $\mathrm{m}$ be the marginal product of this scope. ${ }^{10}$ For some hauls and shippers, service activities are valuable (high $\mathrm{m}$ ), and for some they are less valuable. Motivating high service levels is costly, since it involves monitoring the mix of activities that the driver is performing. Let $\sigma$ be a parameter that captures the ability of the carrier to monitor the driver's efficiency in performing high-service activities: the higher is $\sigma$, the lower is the marginal cost of monitoring. We specify $\mathrm{V}$, the value of using the truck and driver for the shipper's haul, as:

$$
V=\underline{V}+m s-M(s, \sigma)
$$


where $\underline{\mathrm{V}}$ is a fixed quantity, $\mathrm{s}$ is the scope of the driver's activities, $\mathrm{m}$ is the marginal product of this scope, $\sigma$ is the degree to which the carrier can monitor driver activities, and $M(s, \sigma)$ is agency costs. We assume $\mathrm{M}_{1}>0, \mathrm{M}_{2}<0, \mathrm{M}_{12}<0$.

Given this set-up, the optimal amount of scope in the driver's job depends on the costs and benefits of such scope. Assuming an interior solution, optimal job design sets scope such that $\mathrm{m}=\mathrm{M}_{1}\left(\mathrm{~s}^{*}, \sigma\right)$. Raising the marginal product of scope (raising $\mathrm{m}$ ) or raising the firm's ability to monitor driver activities (raising $\sigma$ ) raises the optimal amount of scope. We assume that this expression is invertible, so that we can express the result as $\mathrm{s}^{*}=\phi(\mathrm{m}, \sigma)$.

\section{Load Matching}

Following the discussion in section 2, we assume that search for complementary hauls adds value. Value is increasing in search levels because more effort produces better matches. We also assume that the marginal productivity of search is reduced when drivers are assigned more service-oriented activities. Finally, we allow the productivity of search to be lower if search is done by private fleet dispatchers rather than intermediaries.

We specify the value added of search for complementary hauls as:

$$
\lambda\left(g_{1}-\theta s\right) e_{1}
$$

where $\mathrm{e}_{1}$ is the effort toward finding complementary hauls and $\mathrm{g}_{1}$ is the marginal product of this effort for hauls involving no service. $\theta$ captures the extent to which high service levels reduce the marginal product of search, $\theta>0$. We also assume $\theta<\mathrm{g}_{1} / \phi(\mathrm{m}, \sigma)$; this regularity condition ensures that the marginal benefit of searching for complementary hauls is positive at the optimum. ${ }^{11} \lambda$ is a discount factor that parameterizes the efficiency of search; $\lambda=1$ when search is conducted by intermediaries -- for-hire carriers' dispatchers or brokers -- and $0 \leq \lambda \leq 1$ when it is conducted by private fleet dispatchers. $\lambda$ will tend to be low for private fleet dispatchers for

\footnotetext{
${ }^{10}$ Our equation of scope with service levels reflects an (unmodeled) assumption that some significant amount of driving is always part of the driver's job: the driver is never doing mostly service. Thus, more service involves a greater mix of activities.
} 
city-pairs on which their internal customer ships low volumes. We specify the cost of searching for complementary hauls as $\mathrm{C}_{1}\left(\mathrm{e}_{1}\right)=\mathrm{e}_{1}^{2} / 2$.

We can now calculate an expression for total value, which is the value of using the truck and driver for the shipper's haul plus the value created by search, less the costs associated with search.

$$
T V=\underline{V}+\lambda\left(g_{1}-\theta s\right) e_{1}-C_{1}\left(e_{1}\right)+m s-M(s, \sigma)
$$

We can also solve for shippers' optimal choice of $\mathrm{e}_{1}$, given that they search for complementary hauls themselves using their own dispatchers. Maximizing TV with respect to $\mathrm{e}_{1}$, we find:

$$
e_{1}^{S}=\lambda\left(g_{1}-\theta s\right)
$$

Total value as a function of $\mathrm{s}$ for this option is therefore:

$$
T V_{S}=\underline{V}+1 / 2 \lambda^{2}\left(g_{1}-\theta s\right)^{2}+m s-M(s, \sigma)
$$

We will use this expression later in determining the optimal organizational form.

We turn next to situations where shippers rely on brokers or for-hire carriers to search for complementary hauls. These situations are more complicated because shippers bargain with these other parties over the surplus generated by search.

\section{Bargaining, Truck Ownership, and Residual Rights of Control}

The timing of the model is such that carriers and brokers can search for alternative uses of the truck before they negotiate with shippers over the terms of trade. These activities yield potential uses of the truck that are close substitutes for the shipper's haul. For simplicity, we assume that this search is over alternatives that involve the same level of driver service, but that using the truck and driver for the alternative is always less valuable than using them for the first shipper's haul (perhaps because the alternative haul's origin is more distant). Assume that the value created when the truck is used for an alternative shipper's haul is:

\footnotetext{
${ }^{11}$ This guarantees that $g_{1}-\theta s *$ is non-negative in the results below. The condition ensures that benefits of service are never so high so that the direct benefits of searching for complementary hauls are overwhelmed by its indirect costs.
} 


$$
P=g_{2} e_{2}+\left(g_{1}-\theta s\right) e_{1}+m s-M(s, \sigma)
$$

where $e_{2}$ represents effort toward finding alternative hauls and $g_{2}$ represents the marginal productivity of this effort. ${ }^{12}$ This formulation assumes that $\mathrm{e}_{1}$, the effort that the dispatcher expends toward finding hauls that complement the first shipper's hauls, is equally valuable for the alternative shipper's hauls (e.g., the backhaul she finds would complement either outbound haul.). We specify the cost of searching for substitute hauls as $C_{2}\left(e_{2}\right)=e_{2}^{2} / 2$.

We can now calculate the amount of search when carriers or brokers search for hauls. We assume that when shippers bargain with either for-hire carriers or brokers over the surplus, they split the difference between the value of the haul and the value of the carrier's or broker's outside alternative. A for-hire carrier's outside option is equal to $\mathrm{P}$, the value of using the truck for an alternative shipper's haul. A broker does not have this outside option, because it does not own trucks. We therefore normalize brokers' outside option to zero.

A for-hire carrier chooses $\mathrm{e}_{1}$ and $\mathrm{e}_{2}$ to maximize:

$$
(V+P) / 2-1 / 2 e_{1}-1 / 2 e_{2}=\left(\underline{V}+2\left(g_{1}-\theta s\right) e_{1}+2 m s-M(s, \sigma)+g_{2} e_{2}\right) / 2-1 / 2 e_{1}-1 / 2 e_{2}
$$

This yields search effort equal to:

$$
e_{1}^{F}=\left(g_{1}-\theta s\right), e_{2}^{F}=1 / 2 g_{2}
$$

If search is completed by a for-hire carrier, it will search both for hauls that complement and substitute for the shipper's. Total value under this organizational alternative is:

$$
T V_{F}=\underline{V}+1 / 2\left(g_{1}-\theta s\right)^{2}-1 / 8 g_{2}^{2}+m s-M(s, \sigma)
$$

A broker chooses $\mathrm{e}_{1}$ and $\mathrm{e}_{2}$ to maximize:

$$
V / 2-1 / 2 e_{1}-1 / 2 e_{2}=\left(\underline{V}+\left(g_{1}-\theta s\right) e_{1}+m s-M(s, \sigma)\right) / 2-1 / 2 e_{1}-1 / 2 e_{2}
$$

yielding effort of:

$$
e_{1}^{B}=1 / 2\left(g_{1}-\theta s\right), e_{2}^{B}=0
$$

Brokers search less intensively for complements, and not at all for substitutes. Total value under this alternative is:

\footnotetext{
${ }^{12}$ Thus, $\underline{\mathrm{V}}$ is the value of the first shipper's haul (net of service) and $\mathrm{g}_{2} \mathrm{e}_{2}$ is the value of the alternative haul. We assume $\underline{\mathrm{V}}>1 / 2 \mathrm{~g}_{2}^{2}$.
} 


$$
T V_{B}=\underline{V}+3 / 8\left(g_{1}-\theta s\right)^{2}+m s-M(s, \sigma)
$$

\section{Efficient Organizational Forms: Employment, Job Design and Asset Ownership}

We begin the comparison of organizational forms by examining whether a shipper will use a captive dispatcher, or will rely on brokers to help find hauls for its trucks. This trade-off clearly depends on the extent to which brokers' comparative advantage outweighs the problem that they face due to their inability to appropriate the returns from finding good hauls. Using the expressions for $\mathrm{TV}_{\mathrm{S}}$ and $\mathrm{TV}_{\mathrm{B}}$ above, we generate the following proposition:

Proposition 1: Conditional on shippers owning trucks, shippers will use brokers if and only if $\lambda^{2}<3 / 4$.

Proof: See Appendix.

The proof uses the envelope theorem to show that this condition holds even after optimizing over s. Whether shippers use brokers therefore only depends on shippers' comparative disadvantage, and not on the other parameters of the model. This is a useful result because it implies that we can demonstrate our comparative statics with respect to the make-orbuy decision in general by analyzing the comparative statics of this decision with respect to the two "make" cases separately. We begin our main analysis of asset ownership by assuming that shippers use brokers $\left(\lambda^{2}<3 / 4\right)$; we show that the same comparative statics hold if shippers find their own hauls in the Appendix.

In order to compare the total value created by private carriage versus for-hire carriage, we introduce an index variable, $\delta$, that indicates asset ownership. $\delta=1$ indicates for-hire carriage, $\delta=0$ private carriage. Total value as a function of $\mathrm{s}$ and $\delta$ is:

$$
T V(s, \delta)=\underline{V}+1 / 1 / 8(3+\delta)\left(g_{1}-\theta s\right)^{2}-1 / 8 \delta g_{2}^{2}+m s-M(s, \sigma)
$$

Proposition 2: TV $(s, \delta)$ is supermodular in $\left(-s,-m, \delta,-\sigma, g_{1},-g_{2}\right)$ on the domain where $s \geq 0, \delta \in$ $\{0,1\}$, and $0<\theta<g_{1} / \phi(m, \sigma)$.

Proof: Supermodularity requires that TV has non-decreasing differences in (-s, $\left.\mathrm{m}, \delta,-\sigma, \mathrm{g}_{1},-\mathrm{g}_{2}\right)$; this is equivalent to non-negative cross-derivatives when TV is 
continuously twice-differentiable. (Topkis, 1978) All terms except the second term are supermodular in $\left(-\mathrm{s},-\mathrm{m}, \delta,-\sigma, \mathrm{g}_{1},-\mathrm{g}_{2}\right)$ on this domain by inspection. The third term is supermodular if $\mathrm{g}_{1}-\theta \mathrm{s} \geq 0$, which is guaranteed if $\theta<\mathrm{g}_{1} / \phi(\mathrm{m}, \sigma)$. The sum of supermodular functions is supermodular.

This result allows us to apply a theorem from Topkis (1978) (see also Theorem 5 of Milgrom and Shannon (1994)), and generate a set of monotone comparative statics that we can test with data on asset ownership and technology adoption.

Proposition 3: $-s^{*}$ and $\delta^{*}$ are monotone non-decreasing in $\left(-m,-\sigma, g_{1},-g_{2}\right)$ on the domain where $s \geq 0, \delta \in\{0,1\}$, and $0<\theta<g_{1} / \phi(m, \sigma)$. $-s^{*}$ and $\delta^{*}$ are (weak) complements.

Proposition 3 generates predictions that are consistent with several well-known crosssectional patterns in the industry.

One simple prediction is that $\mathrm{s}$ and $\delta$ should be inversely correlated: that is high service is associated with shipper ownership of trucks. This is consistent with the stylized fact that drivers in private fleets engage in more service-related activities than drivers in for-hire fleets. It is also consistent with the assertion made by many shippers that attainment of better service is why they choose private carriage over for-hire carriage. ${ }^{13}$

A second prediction is that $\delta$ should be high when $g_{1}$ is high: that is, for-hire carriage should be more prevalent when effort toward identifying complementary hauls is particularly valuable. This is consistent with the stylized fact that for-hire carriage tends to be used more for small shipments and long-distance shipments than large and short-distance shipments. (See Bureau of the Census (1999b) and Hubbard (2001a) for empirical evidence.)

A third prediction is that $\delta$ should be low when $\mathrm{m}$ is high: for-hire carriage should be used less, the more valuable are drivers' cargo-handling activities. Cross-sectional evidence from Hubbard (2001a) supports this: for example, controlling for the length of the haul and measures

13 "[T]here are some good reasons why private carriage remains attractive to companies. Service is the key consideration. Many companies claim they require a private fleet to provide the high levels of service their customers expect. 'There are companies that decided to outsource their entire fleet, yet came running back to private fleets when the service was not what they expected,' says [John McQuaid of the National Private Truck Council]." (Thomas (1998)). 
of local market thickness, hauls using non-refrigerated vans are less likely to be completed by for-hire carriers than hauls using dump trailers.

A fourth prediction is that $\delta$ should be low when $\mathrm{g}_{2}$ is high; shippers should own trucks in situations where for-hire carriers would have a large incentive to search for substitute hauls. This is consistent with sentiment in the industry that private carriage tends to be used when shippers value flexibility in pick-up times, and results in Hubbard (2001a) that private carriage becomes more prevalent as local markets become thin. Bargaining is more likely when agreements with for-hire carriers are more open-ended, raising firms' incentives to create backup plans. Firms' incentives to do so are particularly acute when markets are thin because there are more quasi-rents at stake.

Our main empirical tests, however, examine relationships between informational improvements enabled by the adoption of on-board computers (OBCs) and changes in ownership. These exploit the predictions that increasing $g_{1}$ should lead firms to (weakly) increase $\delta$, and increasing $\sigma$ should lead firms to (weakly) decrease $\delta$. If the productivity of searching for complementary hauls $\left(\mathrm{g}_{1}\right)$ increases as a result of improved information technology, this should lead to two changes: a shift from private to for-hire carriage and a decrease in the scope of drivers' activities. If firms' ability to monitor the allocation of drivers' effort $(\sigma)$ increases, this should lead directly to increases in the scope of drivers' activities and indirectly to more shipper ownership of trucks.

Proposition 3 implies that sometimes changes in the model's parameters may not result in changes in the optimal organizational structure. One case is of particular interest to us. If $\mathrm{m}=0$, it is optimal to set $\mathrm{s}=0$ because there is no benefit from giving drivers service responsibilities. If this is true, the total value function is:

$$
T V(s, \delta)=\underline{V}+1 / 8(3+\delta) g_{1}^{2}-1 / 8 \delta g_{2}^{2}
$$

If $\mathrm{m}=0, \mathrm{TV}$ is independent of $\sigma$ : there is no multitasking, and no multitasking-related agency problem. Therefore, if $\mathrm{m}=0$, changes in firms' ability to monitor the allocation of drivers' effort $(\sigma)$ should have no effect on asset ownership.

The following section describes $\mathrm{OBCs}$ and generates empirical propositions relating $\mathrm{OBC}$ adoption to ownership changes. 


\section{On-Board Computers and Organizational Change}

\section{On-Board Computers}

Two types of OBCs began to diffuse in the trucking industry in the late 1980s: trip recorders and electronic vehicle management systems (EVMS). ${ }^{14}$ Trip recorders measure trucks' operation. They record when trucks are turned on and off, their speed, sudden accelerations or decelerations, and various engine performance statistics (e.g., fault codes). Dispatchers and fleet managers receive the information trip recorders collect when drivers return to their base at the end of a trip. Drivers give dispatchers a floppy disk or a similar device. Dispatchers upload the information onto a computer, which processes the information and provides reports. These reports indicate how drivers operated the truck; for example, how quickly they drove, how long they allowed trucks to idle, and whether there were any non-scheduled stops. They also indicate how long drivers spent at each stop.

EVMS record the same information trip recorders do, but provide three additional capabilities. One is that they record trucks' geographic location, often using satellite tracking systems. Another is that they can transmit any information they collect to dispatchers in real time. Dispatchers can thus know where trucks are at any point in time. Third, they provide dispatchers a way of initiating communication with drivers. For example, dispatchers can send a text message that updates drivers' schedule. If the message is complicated, dispatchers can send a message that asks drivers to call in. This is a significant advance over the system firms have traditionally used to communicate with drivers who are outside radio range (about 25 miles). Traditionally, firms require drivers to call in every three or four hours. This requires drivers to frequently pull over, stop, and find a phone, even though much of the time neither dispatchers nor drivers have new information to communicate. Without EVMS, dispatchers often find it hard to verify trucks' location and must wait for distant drivers to call in before they can communicate instructions.

As Hubbard (2000) relates, there is an economically important distinction between these

\footnotetext{
${ }^{14}$ See also Baker and Hubbard (2000) and Hubbard (2000).
} 
two devices. Trip recorders are useful for improving incentives, because they provide verifiable information about how trucks were operated. Importantly for this paper, they monitor how long drivers spent driving and how long they spent performing other tasks: this helps mitigate the agency problems associated with more complex job designs. ${ }^{15}$ Trip recorders are not generally useful for improving resource allocation decisions ("coordination"). They do not improve dispatchers' ability to match trucks to hauls in the very short run because they do not supply information in a timely enough fashion. They are generally not used to improve routing decisions made over the longer run - for example, by helping benchmark routes - because firms usually can obtain information about such things as how long routes take by other, less costly means. $^{16}$

In contrast, EVMS are useful for improving both incentives and coordination. Their additional capabilities help dispatchers match trucks to hauls better, thereby increasing capacity utilization. Real-time information about trucks' location helps them schedule backhauls more efficiently, for example. ${ }^{17}$ These capabilities also enable them to communicate schedule changes to drivers in real time. Dispatchers can quickly reroute trucks in response to changes in market conditions. For example, suppose a truck on the road is half-full. If a dispatcher can find a shipper with cargo that can fill the truck, he can send a message to the driver asking him to make an additional pick-up and delivery.

We next discuss our main empirical propositions, which predict how OBC adoption should affect truck ownership. These propositions are based on the premise that trip recorder adoption increases $\sigma$ and EVMS adoption increases both $\sigma$ and $g_{1}$.

${ }^{15}$ An advertised benefit of trip recorders is their ability to help monitor drivers in this way. For example, Atrol claims that its devices can "tell you how effective your drivers are in managing their time." www.atrol.com.

${ }^{16}$ Many firms use software packages to help dispatchers schedule trucks. These packages often use information EVMS collect (for example, trucks' location), but rarely use the information trip recorders collect.

${ }^{17}$ Trade press articles and advertisements emphasize this. An example of a quote from a driver: "Dispatch knows where I am and where I'm headed so before I even get to my destination, they can plan ahead. Quite often I get a load offering over my Qualcomm system before I'm even empty." www.qualcomm.com. Empirical evidence of EVMS' impact on capacity utilization is in Hubbard (2001b), who finds that EVMS has increased loaded miles among adopters by $13 \%$ as of 1997 . 
P1: Overall, trip recorder adoption should lead to more shipper ownership of trucks.

OBCs' incentive-improving capabilities allow carriers to better monitor how drivers allocate time, and thus effort, across tasks. Trip recorder adoption thus raises $\sigma$, which by proposition 3 increases the optimal choice of $\mathrm{s}$ and decreases $\delta$; carrier ownership of trucks should decrease. We cannot test whether trip recorder adoption increases s because the data do not contain information on the scope of drivers' activities, but we can test whether it leads to more shipper ownership of trucks.

P2: $\quad$ EVMS adoption should lead to less of an increase in shipper ownership of trucks than trip recorder adoption, and may lead to less shipper ownership of trucks.

EVMS' coordination-improving capabilities make dispatchers' search more productive, and thus raise $g_{1}$. Knowing where trucks are allows dispatchers to better anticipate when trucks will come free, and hence helps them refine their search. Being able to initiate communications with drivers while they are in their cab enables them to better exploit the opportunities they identify. For example, they can quickly reallocate drivers and trucks across hauls in response to new opportunities. Because EVMS contain both incentive- and coordination-improving capabilities, EVMS adoption should increase both $\sigma$ and $\mathrm{g}_{1}$ and thus has a theoretically ambiguous impact on asset ownership. However, because EVMS adoption increases $\sigma$ in the same way trip recorder adoption does, EVMS adoption should move hauls less toward private carriage than trip recorder adoption.

P3: $\quad$ Trip recorder adoption should increase shipper ownership of trucks more when drivers' cargo-handling activities are potentially productive than when they are not productive. It should not affect whether shippers own trucks when drivers' handling activities are not productive.

Trip recorder adoption should not lead to ownership changes when $\mathrm{m}=0$ : for example 
for hauls of bulk goods or goods that require people other than drivers to load and unload. It should lead to ownership changes when $\mathrm{m}>0$. From above, this should be the case when trucks haul packaged goods, especially when they pick up or deliver to small outlets. It should also be the case when trucks haul goods for which handling requires certification, such as petroleum or chemicals. However, it should not be true for hauls of bulk goods or goods that cannot be lifted or transported with standard equipment.

\section{Data}

The data are from the 1987, 1992, and 1997 Truck Inventory and Use Surveys (TIUS). ${ }^{18}$ The TIUS is a mail-out survey of trucks taken by the Census as part of the Census of Transportation. The Census sends forms to a random sample of truck owners. These forms ask questions about individual trucks' characteristics. Truck owners report the truck's type (pick-up, van, tractor-trailer, etc.), make, model, and many other characteristics. The TIUS also asks how trucks are equipped, including whether they have trip recorders or EVMS installed, and how they are used. Owners report how far from home individual trucks generally operated, the type of trailer to which they were typically attached, the class of product they generally hauled, the state in which they were based, and whether they were used for for-hire or private carriage. Publiclyavailable data from the Survey do not identify trucks' owners because of confidentiality restrictions. This paper uses only observations of truck-tractors (the front halves of tractortrailers) and excludes those that were generally operated off-road, carried household goods (i.e., moving trucks), or were attached to trailers that do not haul goods (e.g., trailers with large winches permanently attached). Eliminating these observations leaves 21,236, 32,015, and 18,856 observations of tractor-trailers in 1987, 1992, and 1997 respectively. This is over $85 \%$ of the tractor-trailers in the original samples.

Figure 1 shows private carriage shares in each of the three years. In each of these years, the overall share is about $50 \%$ and is higher for shorter hauls than longer ones. The overall share

\footnotetext{
${ }^{18}$ See Baker and Hubbard (2000), Bureau of the Census (1995, 1999a), and Hubbard (2000, 2001a) for more on the TIUS. The 1997 survey is actually called the Vehicle Inventory and Use Survey.
} 
fluctuated during this period, increasing from $50.1 \%$ to $54.6 \%$ between 1987 and 1992, then falling back to $51.7 \%$ in 1997 . The time trends differ for hauls of different lengths. The private carriage share increased for all distances between 1987 and 1992. It increased for short hauls but declined for medium and long hauls between 1992 and 1997. This paper's empirical tests examine how these changes relate to the diffusion of on-board computers.

Figure 2 summarizes patterns of $\mathrm{OBC}$ adoption over time and across distances. There are three important patterns. First, adoption of OBCs was rapid during our sample period. In 1987, a negligible number of tractor-trailers had an $\mathrm{OBC}$ installed; we treat this number as zero throughout. In 1992, 19\% of tractor-trailers had an OBC installed; by 1997, adoption increased to $34 \%$. Second, adoption was greater for trucks used for longer hauls. By 1997, half of longhaul trucks had an OBC installed. Third, the composition of OBCs differed in the early and late part of our sample period. Trip recorders made up nearly half of OBC adoption between 1987 and 1992, but there was no net adoption of trip recorders between 1992 and 1997. Evidence from the trade press and interviews suggests that this reflects two offsetting factors: new trip recorder adoption and upgrades from trip recorders to EVMS. In contrast, adoption of EVMS accelerated. The share of trucks with EVMS more than doubled between 1992 and 1997. Thus, broad patterns in the data suggest a correlation between technological and organizational change: the movement from for-hire to private carriage between 1987 and 1992 was during a time when trip recorder adoption was relatively high, and the movement from private to for-hire carriage between 1992 and 1997 was during a time when OBC adoption was disproportionately EVMS.

\section{Cohort Data}

The bulk of our empirical analysis uses cohorts rather than individual trucks as the unit of observation. This allows us to exploit the time dimension of the data and use first-differencing to control for unobserved time-invariant factors that affect $\mathrm{OBC}$ use and the make-or-buy decision independently. Like in our earlier work we define cohorts narrowly, basing them on state-product-trailer-distance combinations; an example is "trucks based in New Jersey hauling chemicals in tank trucks long distances." There are 2773 cohorts with a positive number of observations in 1987, 1992, and 1997. About three-quarters of our original observations are in 
these cohorts.

The characteristics of the trucks in the original and cohort samples are similar with two exceptions. One is that the cohort sample tends not to contain trucks that are predominantly attached to uncommon trailers such as auto trailers, logging trailers, and specialized platformtypes. An implication is that the cohort sample contains a higher fraction of long haul trucks than the population because hauls using specialized trailers tend to be short. The other is that, conditional on distance, trucks attached to refrigerated vans make up a disproportionate share of the cohort sample: about $20 \%$ rather than their $10 \%$ share in the original sample. The reason for this is refrigerated vans almost exclusively haul a single product class: processed food. Refrigerated van cohorts tend to be larger and are less likely to have zero observations than cohorts associated with trailers that haul multiple product classes.

Table 1 contains summary statistics for the cohort sample. Cohorts tend to be based on relatively few observations due to our narrow cohort definition: the number of observations per cohort is less than ten in each year. ${ }^{19}$ The average private carriage share is about $50 \%$ and average OBC adoption rates are similar to those in Figure 2. Table 2 provides evidence of relationships between technological adoption and organizational change at the cohort level. The top panel uses cohorts with positive observations in both 1987 and 1992. The first row indicates that averaging across cohorts, the private carriage share increased from 0.49 to 0.50 between 1987 and 1992. The next three rows split the cohort sample according to OBC adoption. On average, the private carriage share stayed the same for cohorts with low OBC adoption. Among cohorts with high $\mathrm{OBC}$ adoption, the private carriage share increased for those where trip recorder adoption was high but decreased slightly for those where EVMS adoption was high. The bottom panel reports results from a similar exercise that analyzes patterns between 1992 and 1997. The private carriage share decreased for the low OBC and high EVMS adoption cohorts (slightly more for the latter), but increased for high trip recorder adoption cohorts.

\footnotetext{
${ }^{19}$ In earlier versions of this paper, we reported estimates of our main specifications using the subsample of cohorts where the private and for-hire carriage shares are positive in each year. The average cohort size is about double in this subsample, but observations in these cohorts make up only about $35 \%$ of the original sample. We showed that our main results do not change.
} 
In sum, relationships between $\mathrm{OBC}$ adoption and organizational change differ for trip recorders and EVMS. Cohorts with high trip recorder adoption moved toward private carriage more than cohorts with low OBC adoption. Cohorts with high EVMS adoption moved toward for-hire carriage slightly more than those with low OBC adoption, but this difference is very small. Nevertheless, the fact that cohorts with high EVMS adoption did not move toward private carriage is interesting in light of the fact that EVMS enable the same contractual improvements trip recorders do. This suggests EVMS' resource allocation-improving capabilities - which trip recorders do not have - have organizational implications that offset those of their incentiveimproving ones.

\section{Results}

Our base specification takes the form:

$$
y_{i t}=x_{i t} \beta+\phi_{i}+\varepsilon_{i t}
$$

where $y_{i t}$ is the for-hire carriage share in cohort $i$ at time $t, x_{i t}$ includes a vector of explanatory variables, and $\phi_{\mathrm{i}}$ and $\varepsilon_{\mathrm{it}}$ represent unobserved time-invariant and time-varying variables that affect optimal organizational form. The variables of interest in $\mathrm{x}_{\mathrm{it}}$ are $\mathrm{OBC}$, the share of trucks with either class of OBC installed, and EVMS, the share of trucks with EVMS installed. The coefficient on $\mathrm{OBC}$ therefore picks up the relationship between OBCs' incentive-improving capabilities and asset ownership and that on EVMS picks up the relationship between EVMS' coordination-improving capabilities and asset ownership. The control variables in $\mathrm{x}_{\mathrm{it}}$ are similar to those in Table 5 in Hubbard (2001a). They include a full set of dummy variables that indicate the cohort's trailer type (dry van, refrigerated van, tank truck, etc.), a dummy that equals one if the cohort is of trucks hauling mixed cargo, and $\ln$ (trailer density). Trailer density is the number of trucks in the state attached to a given trailer type, normalized by the state's urbanized area, and is a proxy for local market thickness for hauls using a particular trailer type. We allow the coefficients on the dry van and auto trailer dummies to vary across years to account for secular changes in contractual form over time (see Hubbard (1998)).

Most of our results will be from first-difference specifications:

$$
y_{i t}-y_{i(t-1)}=\left(x_{i t}-x_{i(t-1)}\right) \beta+\eta_{i t}
$$


where $\eta_{\mathrm{it}}=\varepsilon_{\mathrm{it}}-\varepsilon_{\mathrm{i}(t-1)}$. First differencing mitigates an important class of endogeneity problems that would appear in cross-sectional analysis. For example, suppose that when shipping patterns are regular, private carriage tends to be used more (perhaps because intermediaries' efforts are less valuable) and trip recorders are disproportionately valuable relative to EVMS. This would lead private carriage and trip recorder use to be correlated in the cross-section even if trip recorders adoption did not cause truck ownership to change. First differencing effectively allows us to control for unobserved time-invariant variables that could affect $\mathrm{OBC}$ adoption and organizational form independently, and base inferences on relationships between adoption and changes in asset ownership rather than levels. ${ }^{20}$ Thus, if hauls' unobserved regularity is constant over time, first-differencing eliminates this as a possible endogeneity problem. For simplicity, our initial discussion of the results will assume $\eta_{i t}$ to be independent of adoption: that is, we assume changes in unobserved haul characteristics to be independent of adoption. Later we will relax this assumption and present instrumental variables estimates of the first-difference specifications.

Table 3 contains two sets of regression estimates that use cohort data from 1987, 1992, and 1997. The first column presents levels estimates; the second presents first-difference estimates. The coefficients on OBC are negative and significant and those on EVMS are positive and significant in both columns. They are about $40 \%$ lower in absolute value when moving from the levels to the first-difference estimates, but remain statistically significant and economically important. The first-difference estimates imply that all else equal, cohorts with a 20 percentage point higher trip recorder adoption rate experienced a 2 percentage point greater increase in their private carriage share. Likewise, moving 20 percent of trucks from trip recorders to EVMS corresponds to a 3 percentage point increase in the for-hire carriage share.

These estimates supply evidence consistent with our main propositions. Consistent with $\mathrm{P} 1$, trip recorder adoption is associated with movement from for-hire to private carriage. Consistent with P2, EVMS adoption is less associated with such movement. Assuming these

\footnotetext{
${ }^{20}$ The control variables in the first difference specifications only include the dry van and auto trailer dummies and $\ln$ (trailer density) because none of the coefficients on the other controls vary over time. Changes in unobserved
} 
reflect causal relationships, they indicate that OBCs' incentive- and coordination-improving capabilities affect the make-or-buy margin differently. Their incentive-improving capabilities move hauls from "buy" to "make;" their coordination-improving capabilities move them from "make" to "buy." The former shifts truck ownership from for-hire carriers to shippers; the latter from shippers to for-hire carriers.

Table 4 breaks these results down further. The top panel reports first-difference estimates using all cohorts and subsamples of short, medium, and long haul cohorts. The coefficient on $\mathrm{OBC}$ is negative for all three subsamples and statistically significant for medium and long haul cohorts. The EVMS coefficient is positive and significant for all three subsamples, and of about the same magnitude. The basic relationships between adoption and changes in asset ownership hold across hauls of different distances.

The bottom part of the table estimates the coefficients using only 1987 and 1992, then only 1992 and 1997 data. In the earlier period, the pattern of a negative coefficient on OBC and a positive one on EVMS only appears within the long haul subsample. In contrast, this pattern appears strongly and consistently in the later period. In the latter period, the coefficients on OBC are negative in each subsample, and statistically significant for the short and medium haul subsample. Those on EVMS are positive and significant in each subsample. The cross-year differences are interesting because they are consistent with widespread speculation that organizational changes tend to lag IT adoption, even when they are complementary.

\section{Interactions: Multitasking Tests}

In the model, trip recorders affect optimal asset ownership indirectly, by lowering the agency costs associated with multitasking. If so, then the $\mathrm{OBC}$ coefficient should only be negative for hauls where drivers' cargo-handling effort is potentially productive. This is the basis of $\mathrm{P} 3$ above. To examine this, we create interactions between $\mathrm{OBC}$ adoption and product categories. One set is between adoption and a dummy variable that equals one if the cohort hauls processed food or mixed cargo. Trucks hauling processed food or mixed cargo tend to deliver packaged goods to retail outlets. Drivers' cargo handling efforts are potentially more valuable 
when they haul these goods than other, bulkier goods. The other set is between adoption and a dummy variable that equals one if the cohort hauls petroleum or chemicals, cargo for which handling requires certification. We therefore test whether the $\mathrm{OBC}$ coefficient is more negative for these "multitasking" cohorts than others.

Table 5 summarizes the results. The first column uses data from all three years. The coefficient on OBC alone is small and statistically insignificant. There is no relationship between OBC adoption and asset ownership when trucks haul goods in the omitted category, which contains raw materials and bulky goods. ${ }^{21}$ The interactions on OBC*(food or mixed cargo) and on $\mathrm{OBC}^{*}$ (petroleum or chemicals) are both negative, and the former is statistically significant. The other two columns report estimates using only two of the years. The OBC own effects are statistically zero in both periods. Both interactions are negative and significant in the late period of the sample. The estimates provide support for P3, and are important evidence that OBCs' incentive-improving capabilities affect asset ownership through job design. There is no evidence that incentive improvements affect the make-or-buy decision for hauls where drivers' handling efforts are rarely productive. When drivers' handling efforts tend to be productive, hauls for which trip recorders were adopted moved from for-hire to private carriage.

The first difference estimates are thus consistent with all three of our theoretical propositions. The following subsection provides additional evidence regarding whether they indeed reflect causal relationships between adoption and organizational change.

\section{Instrumental Variables Estimates}

As noted above, alternative interpretations of the first difference estimates center on the premise that $\mathrm{OBC}$ adoption and organizational changes might be independently affected by some omitted factor. For example, if hauls' regularity changes over time, and increases more in some cohorts than others, this could lead independently to more private carriage and to trip recorder adoption. This would make adoption econometrically endogenous in the first-difference 
estimates. Similarly, unobserved factors may also explain why EVMS adoption might be correlated with movements toward for-hire carriage. Suppose unobserved shipper characteristics change over time; some shippers may both establish more sophisticated logistics practices and begin to value shipment tracing capabilities. This could lead independently to less private carriage (because drivers' handling effort is less valuable) and increased EVMS adoption.

Below we present instrumental variables estimates of the first-difference specifications. Factors that affect $\mathrm{OBC}$ adoption but do not directly affect organizational form are good instruments. We use four main instruments: the fraction of miles trucks are operated outside of their base state, the number of weeks per year trucks in the state are in use, and dummy variables that equal one if the truck is based in a western state (i.e., west of Missouri), or in a New England state. These are computed at the cohort level; hence, the first two of these are cohort-level averages. Fraction of miles out of state affects OBC adoption because drivers must keep track of how many miles trucks are operated in each state. State fuel taxes are paid on this basis. OBCs let drivers enter in this information on a keypad and lower data entry and processing costs when trucks' owners calculate the tax they owe each state. This is more valuable for trucks that spend more time outside of their base state because they cross state lines more. State averages for number of weeks in use differ considerably across states, ranging between 35 and 45 weeks, and reflect differences in the cyclicality of truck shipments. Much of this variation is likely climaterelated, as the bottom five states are Montana, Wyoming, North Dakota, Alaska, and South Dakota. Trucks are idled more weeks per year, and OBCs' benefits are correspondingly lower, in areas where shipments are highly cyclical. We assume that statewide averages in the number of weeks trucks are in use are unaffected by OBC adoption. ${ }^{22}$ The two regional dummies are included because it is traditionally more difficult for drivers to contact dispatchers quickly in less densely populated areas. This is one reason why adoption tends to be above average in the west

\footnotetext{
${ }^{21}$ The most prevalent product classes in the omitted category are fresh farm products, building materials, machinery, and lumber and wood products. About $70 \%$ of cohorts are in the omitted category; about $30 \%$ are in the "multitasking" categories.
} 
but below average in New England. We use these four variables and their interactions as instruments for $\mathrm{OBC}$ and EVMS. Table A1 reports estimates from four simple "first-stage" specifications that regress cohort-level trip recorder and EVMS adoption in the early and late sample periods on the four instruments and a vector of controls.

Table 6 contains estimates from specifications analogous to that in the first column of Table 5, but which restrict the interaction terms to be the same across the four "multitasking" product types. Looking at the first column, the coefficient on $\mathrm{OBC}$ is nearly zero; as before, there is no evidence that trip recorders affect asset ownership for the "non-multitasking" cohorts. The same is true for the EVMS*Mult interaction: there is no evidence that OBCs' coordinationimproving capabilities' impact differs with whether multitasking is potentially productive. The negative coefficient on $\mathrm{OBC} *$ Mult suggests that trip recorders move hauls toward private carriage more for the multitasking cohorts than the non-multitasking ones. The positive coefficient on EVMS suggests that EVMS' coordination improving capabilities move hauls from private to for-hire carriage. However, these coefficients are not statistically significantly different from zero because they are not estimated precisely. The noisiness of the estimates reflects that while three of our instruments are predictors of $\mathrm{OBC}$ adoption in general, none of them shift trip recorder adoption but not EVMS adoption. (See Table A1.) This makes it hard to distinguish between the organizational effects of $\mathrm{OBCs}$ ' incentive- and coordination-improving capabilities in the instrumental variables estimates.

The bottom part of the table contains estimates of (OBC+EVMS) and $(\mathrm{OBC}+\mathrm{EVMS}) *$ Mult, which reflect EVMS' overall organizational impact. We can estimate these more precisely; consistent with our earlier results, EVMS adoption pushes hauls toward for-hire carriage, but does so less for the multitasking cohorts than the non-multitasking cohorts. The right column restricts the coefficient on $\mathrm{OBC}$ to zero for the non-multitasking cohorts, a restriction suggested by the near-zero point estimates on this coefficient in Table 5. The sign and significance of the remaining three coefficients are the same as in the first-difference estimates.

\footnotetext{
${ }^{22}$ Individual trucks with OBCs do tend to be used more weeks than those without them, because trucks without OBCs are more likely to be idled when demand is low. But OBC adoption should have a minimal impact
} 
In sum, our instrumental variables estimates provide no evidence that our first-difference estimates reflect non-causal relationships. Although we cannot statistically distinguish between the impact of OBCs' incentive- and coordination-related capabilities to the same degree, the qualitative patterns that we are able to identify are similar to those in our earlier results.

\section{Magnitudes}

Although not the main focus of the study, we can also use our estimates to investigate the degree to which overall changes in the private carriage share between 1987 and 1997 were due to the diffusion of OBCs. Table 7 summarizes our analysis. The top line reports the actual private carriage shares in our sample in each of the three years. The bottom part of the table reports the estimated shares, absent OBC diffusion, computed using the simple and GMM-IV first difference estimates from the right parts of Tables 6 and 7. The simple first-difference estimates suggest that OBCs had little overall impact between 1987 and 1992 - the diffusion of trip recorders and EVMS had offsetting effects - but caused about one percentage point of the overall 2.9 percentage point decline between 1992 and 1997. The GMM-IV point estimates from the imply that OBCs' overall impact was much larger. They indicate that absent $\mathrm{OBC}$ diffusion, the private carriage share would have continued to increase to almost $60 \%$ by 1997 . One interpretation is that the organizational impact of EVMS' coordination-improving effects worked against a broad increase in the demand for high service levels.

We do not put a large weight on these quantitative conclusions, in large part because the GMM-IV point estimates in Table 6 are noisy. We are more confident in stating the qualitative conclusion that overall, OBC diffusion played a significant and possibly large role in inducing shippers to outsource more during the 1990s.

\section{Conclusion}

In this paper, we combine recent theoretical work from organizational economics with a detailed and disaggregated dataset to gain insight about the interaction between asset ownership, 
job design, and information. Of particular importance is our ability to distinguish between informational changes that lead either to better monitoring of agents, or to better coordination of activities. We believe that our results - that improved monitoring technologies lead shippers to vertically integrate into trucking, while technologies that improve coordination lead to more outsourcing of trucking services - highlight the respective advantages of firms and markets in the economy, and thus shed light on their roles in the operation and development of economic systems.

In describing and explaining the development of $19^{\text {th }}$ century capitalism, Chandler (1977) and others have argued that the development of new communication technologies (e.g., the telegraph) enabled the growth of large, integrated firms. Large transportation, manufacturing, and retailing firms were impossible without a technology that enabled managers to coordinate large-scale economic activity. Yet we have found exactly the opposite effect in late $20^{\text {th }}$ century trucking: a new communications technology that improved coordination led to smaller, less integrated firms. Why the difference?

We believe that our new results arise because we distinguish between informational changes that improve coordination from those that improve incentives. Such a capability is rare in empirical work on organizations. Yet it is essential to understanding the true role of firms and markets as competing mechanisms for organizing economic activity. Hayek (1945) argued that the true value of the market-based price system is its ability to utilize dispersed information about resources and coordinate their use in a way that no centrally planned economy (or firm) ever could. Given this comparative advantage of markets over firms, it is not surprising that a technological change that mitigates the Hayekian coordination problem should lead to a greater relative improvement in the efficiency of markets.

Holmstrom and Milgrom (1994) and Holmstrom (1999), by contrast, argue that the true advantage of firms over markets is their ability to craft delicately balanced incentives for agents engaged in multiple activities, in a way that the strong incentives generated by markets and asset ownership cannot. Given this comparative advantage for firms, it is again not surprising that a technological change that mitigates contracting problems should lead to a greater relative improvement in the efficiency of firms. 
Information costs are at the core of nearly all economic theories of organizations. Thus, all of these theories predict that changes in information technology that change the cost of contracting and communication will affect the organization of economic activity. We find that the answer to the question: "Has IT adoption led to larger or smaller firms in trucking?" is "Yes," and show how the organizational implications of IT's incentive- and coordination-improving capabilities systematically differ. Future research will further inform debates regarding the organizational implications of changes in information costs by investigating whether this systematic difference in trucking is general. 


\section{Appendix}

\section{Proof of Proposition 1:}

Equations (5) and (12) both take the form:

$$
T V=\underline{V}+1 / 2 a\left(g_{1}-\theta s\right)^{2}+m s-M(s, \sigma)
$$

By the envelope theorem,

$$
\frac{d T V\left(a, s^{*}(a)\right)}{d a}=\frac{d T V\left(s^{*}\right)}{d a}=\frac{1}{2}\left(g_{1}-\theta s^{*}\right)
$$

The right hand side is positive if $\theta<\mathrm{g}_{1} / \phi(\mathrm{m}, \sigma)$. Therefore, TV is strictly increasing in a, and thus $\mathrm{TV}_{\mathrm{S}}>\mathrm{TV}_{\mathrm{B}}$ iff $\lambda^{2}>3 / 4$ since $\mathrm{a}=\lambda^{2}$ in (5) and $\mathrm{a}=3 / 4$ in (12).

Q.E.D.

Demonstration of Comparative Statics When $\lambda^{2}>3 / 4$ :

When $\lambda^{2}>3 / 4$, shippers find their own hauls rather than using brokers. Equation (13) becomes:

$$
\begin{aligned}
T V(s, \delta) & =\underline{V}+1 / 2\left[\lambda^{2}(1-\delta)+\delta\right]\left(g_{1}-\theta s\right)^{2}-1 / 8 \delta g_{2}^{2}+m s-M(s, \sigma) \\
& =\underline{V}+1 / 2\left[\lambda^{2}+\delta\left(1-\lambda^{2}\right)\right]\left(g_{1}-\theta s\right)^{2}-1 / 8 \delta g_{2}^{2}+m s-M(s, \sigma)
\end{aligned}
$$

Propositions 2 and 3 hold for this expression by the same logic as in the text. 


\section{References}

Baker, George P. (1992). "Incentive Contracts and Performance Measurement." Journal of Political Economy, 100, 598-614.

Baker, George P., and Thomas N. Hubbard (2000). "Contractibility and Asset Ownership: OnBoard Computers and Governance in U.S. Trucking." NBER Working Paper \#7634, April 2000.

Brynjolfsson, Erik, and Lorin Hitt, "Information Technology and Organizational Design: Some Evidence From Micro Data," Stanford University, October 1997.

Bureau of the Census (1995). 1992 Census of Transportation: Truck Inventory and Use Survey. Washington, DC: Government Printing Office.

Bureau of the Census (1999a). 1997 Census of Transportation: Vehicle Inventory and Use Survey. Washington, DC: Government Printing Office.

Bureau of the Census (1999b). 1997 Census of Transportation: Commodity Flow Survey. Washington, DC: Government Printing Office.

Deaton, Angus (1985). "Panel Data from Time Series of Cross-Sections," Journal of Econometrics, 30, 109-26.

Chandler, Alfred P. (1977). The Visible Hand: The Managerial Revolution in American Business. Cambridge, MA: Belknap.

Grossman, Sanford, and Oliver Hart (1986). "The Costs and Benefits of Ownership: A Theory of Vertical and Lateral Integration." Journal of Political Economy, 94, 691-719.

Hayek, F. A. (1945). "The Use of Knowledge in Society." American Economic Review, 35, 519-530.

Holmstrom, Bengt (1999). "The Firm as a Subeconomy." Journal of Law, Economics, and Organization, 15, 74-102.

Holmstrom, Bengt, and Paul Milgrom (1991). "Multitask Principal-Agent Analyses: Incentive Contracts, Asset Ownership, and Job Design." Journal of Law, Economics, and Organization, 7, 24-52.

Holmstrom, Bengt, and Paul Milgrom (1994). "The Firm as an Incentive System." American Economic Review, 84, 972-991. 
Hubbard, Thomas N. (1998). "Governance Structure in the Deregulated Trucking Industry." UCLA, October 1998.

Hubbard, Thomas N. (2000). "The Demand for Monitoring Technologies: The Case of Trucking." Quarterly Journal of Economics, 115, 533-576.

Hubbard, Thomas N. (2001a). "Contractual Form and Market Thickness in Trucking." Rand Journal of Economics, 32, 369-386.

Hubbard, Thomas N. (2001b). "Information, Decisions, and Productivity: On-Board Computers and Capacity Utilization in Trucking." NBER Working Paper \#8525, September 2001.

Jensen, Michael C., and William H. Meckling (1976). "Theory of the Firm: Managerial Behavior, Agency Costs, and Ownership Structure." Journal of Financial Economics, 3, 305360 .

Jensen, Michael C., and William H. Meckling (1992). "Specific and General Knowledge, and Organizational Structure," in Contract Economics, Lars Werin and Hans Wijkander, eds. Cambridge, England: Blackwell.

Leavitt, H. J., and T. L. Whisler (1958). "Management in the 1980s." Harvard Business Review, $36,41-48$.

Malone, Thomas W., JoAnne Yates, and Robert I. Benjamin (1987). "Electronic Markets and Electronic Hierarchies." Communications of the ACM, 30, 484-497.

Milgrom, Paul and John Roberts (1990). "Bargaining Costs, Influence Costs, and the Organization of Economic Activity," in Perspectives on Positive Political Economy, James E. Alt and Kenneth A. Shepsle eds., Cambridge: Cambridge University Press.

Milgrom, Paul, and Chris Shannon (1994). "Monotone Comparative Statics." Econometrica, 62, 157-180.

Ouellet, Lawrence J. (1994). Pedal to the Metal: The Work Lives of Truckers. Philadelphia, PA: Temple.

Thomas, Jim (1998). "Private Fleets: Down But Not Out." Logistics Management and Distribution Report, 37(7), 31-32.

Topkis, Donald M. (1978). "Minimizing a Submodular Function on a Lattice." Operations Research, 26, 305-321. 
Figure 1

Private Carriage Share by Year, Distance of Haul

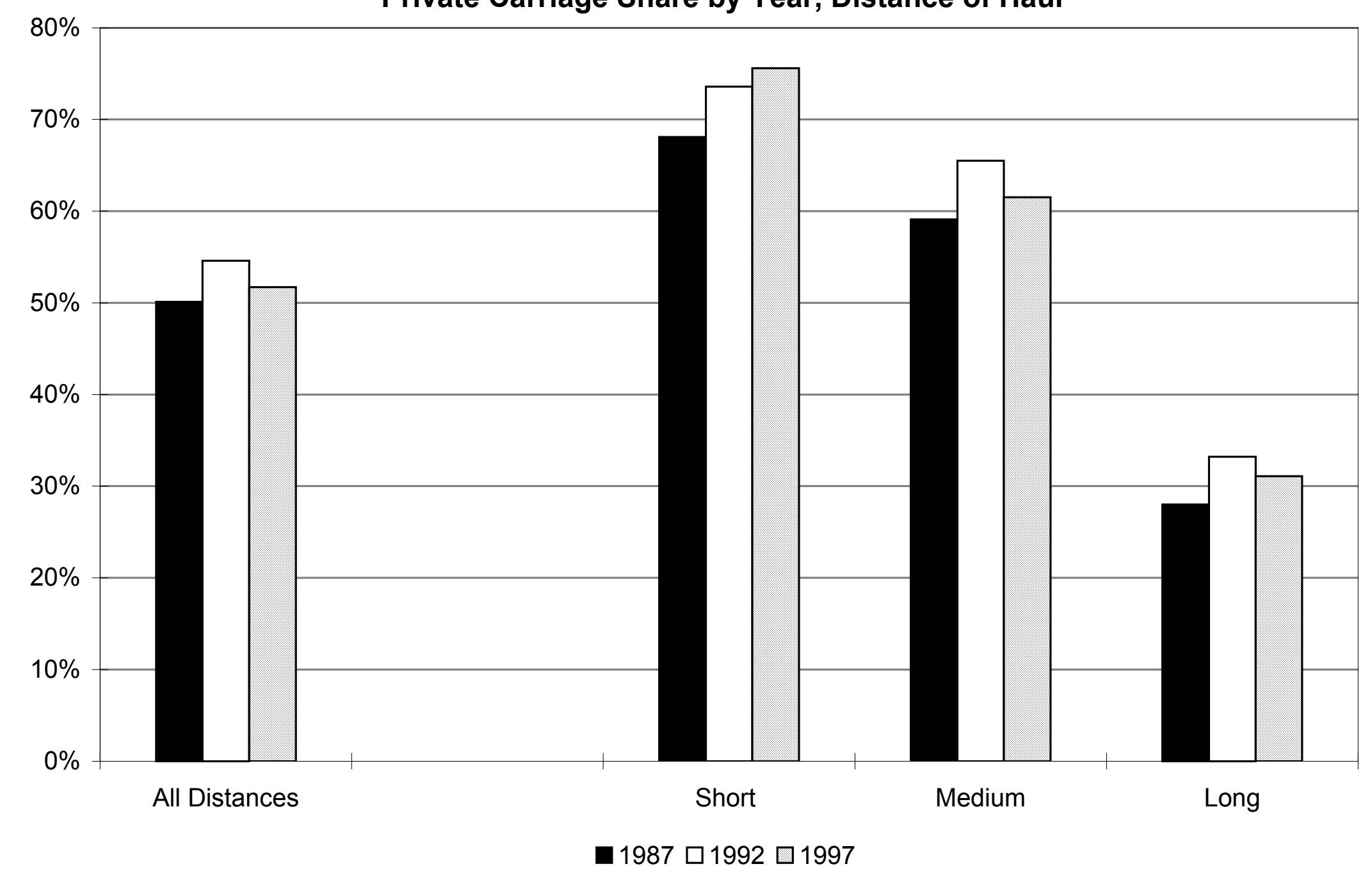


Figure 2

OBC Adoption by Year, Distance of Haul

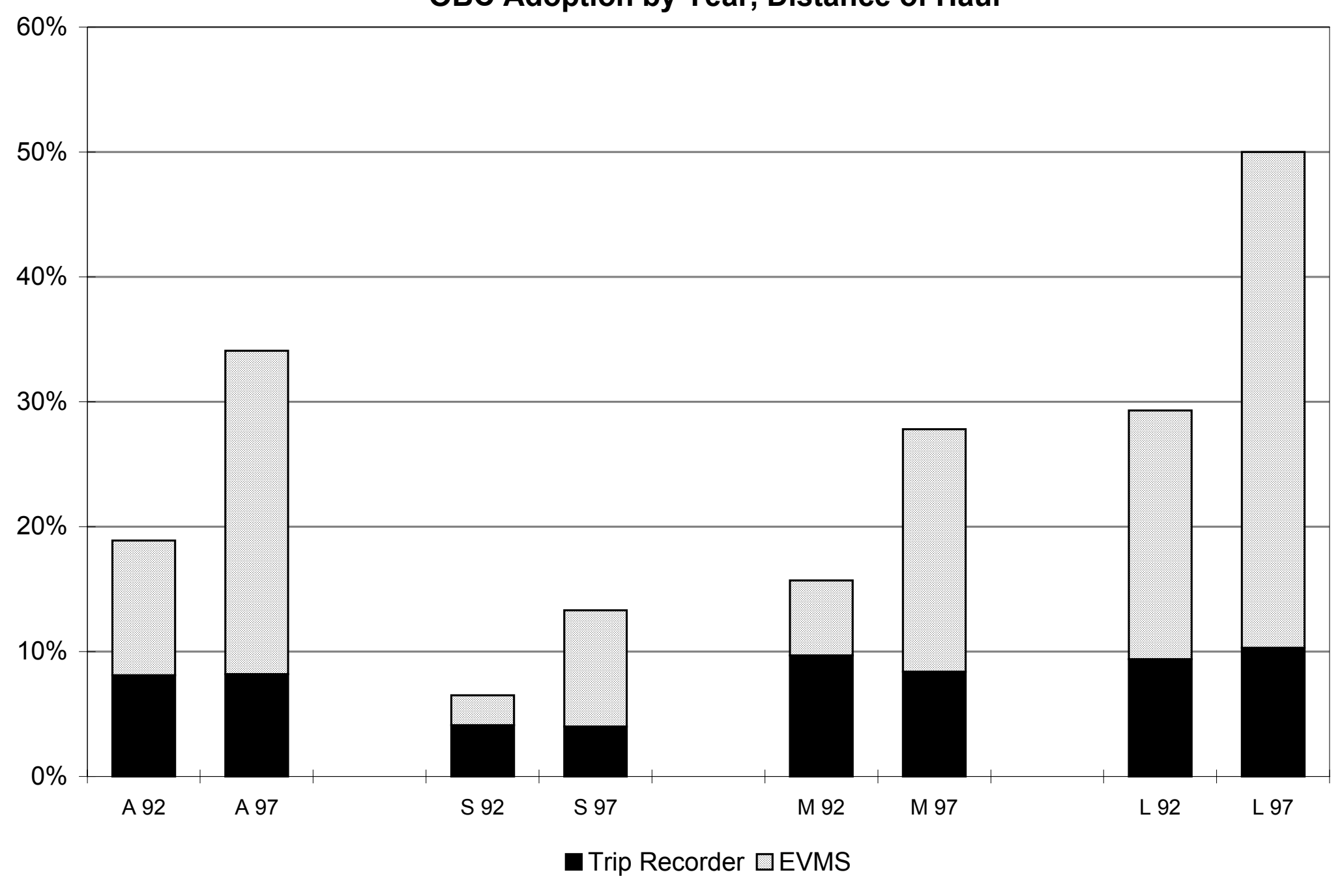




\section{Table 1}

\section{Cohort Summary Statistics}

Positive Number of Observations in:

Cohorts

Observations/Cohort, 1987

Observations/Cohort, 1992

Observations/Cohort, 1997

Private Carriage Share, 1987

Private Carriage Share, 1992

Private Carriage Share, 1997

Trip Recorder Adoption, 1987-1992

EVMS Adoption, 1987-1992

Trip Recorder Adoption, 1992-1997

EVMS Adoption, 1992-1997
$1987,1992,1997 \quad 1987,1992 \quad 1992,1997$

$\begin{array}{lll}2773 & 3908 & 4101\end{array}$

$\begin{array}{ll}5.7 & 4.7\end{array}$

$8.3 \quad 6.6$

$0.50 \quad 0.49$

$0.50 \quad 0.50 \quad 0.52$

$0.48 \quad 0.50$

$\begin{array}{lll}0.08 & 0.08 & 0.08\end{array}$

$\begin{array}{lll}0.08 & 0.09 & 0.11\end{array}$

$\begin{array}{ll}-0.01 & 0.00\end{array}$

$0.16 \quad 0.16$

Averages are computing using weights, where weight $=\left(\right.$ numobs $87^{*}$ expanf $87+$ numobs $92^{*}$ expanf $92+$ numobs $97^{*}$ expanf 97$) / 3$ for samples using all three years.

Analogous weights are used for samples that use only two of the three years. 
Table 2

Private Carriage Share and OBC Adoption

Cohort Data

\begin{tabular}{|c|c|c|c|c|c|c|}
\hline & \multicolumn{3}{|c|}{ Mean Private Carriage Share } & \multicolumn{2}{|c|}{ OBC Adoption, 1987-1992 } & \multirow[b]{2}{*}{$\mathrm{N}$} \\
\hline & 1987 & 1992 & Change & Trip Recorder & EVMS & \\
\hline All Cohorts & 0.49 & 0.50 & 0.01 & 0.08 & 0.09 & 3908 \\
\hline Low OBC Adoption Cohorts & 0.54 & 0.54 & 0.00 & 0.02 & 0.02 & 2972 \\
\hline High TR Adoption Cohorts & 0.50 & 0.54 & 0.04 & 0.34 & 0.06 & 470 \\
\hline \multirow[t]{3}{*}{ High EVMS Adoption Cohorts } & 0.33 & 0.32 & -0.01 & 0.05 & 0.36 & 466 \\
\hline & \multicolumn{3}{|c|}{ Mean Private Carriage Share } & \multicolumn{2}{|c|}{ OBC Adoption, 1992-1997 } & \\
\hline & 1992 & 1997 & Change & Trip Recorder & EVMS & $\mathrm{N}$ \\
\hline All Cohorts & 0.52 & 0.50 & -0.02 & 0.00 & 0.16 & 4101 \\
\hline Low OBC Adoption Cohorts & 0.57 & 0.55 & -0.02 & -0.05 & 0.02 & 2756 \\
\hline High TR Adoption Cohorts & 0.50 & 0.54 & 0.04 & 0.37 & 0.02 & 263 \\
\hline High EVMS Adoption Cohorts & 0.42 & 0.39 & -0.03 & -0.02 & 0.43 & 1082 \\
\hline
\end{tabular}

The top (bottom) panel includes all cohorts with a positive number of observations in both 1987 and 1992 (1992 and 1997).

Low OBC Adoption Cohorts are those where OBC adoption was less than 0.15.

High TR Adoption Cohorts are those where OBC adoption was greater than 0.15, and TR adoption was greater than EVMS adoption.

High EVMS Adoption Cohorts are those where OBC adoption was greater than 0.15 , and EVMS adoption was greater than TR adoption. 


\section{Table 3}

\section{OBC Adoption and Asset Ownership}

Dependent Variable:

For-Hire Carriage Share

Levels Estimates First-Differences

$\mathrm{OBC}$
$-0.144$

(0.021)

0.239

(0.024)
$-0.090$

(0.024)

0.149

(0.028)

SUR estimates.

Sample includes all cohorts with positive number of observations in 1987, 1992, and 1997; N = 2773 .

Cohorts are weighted using Census' weighting factors, number of observations.

Specifications include trailer dummies, mixed cargo dummy, distance dummies, and In(trailer density) as controls, and allow the coefficient on the auto trailer and van dummy to vary across years to account for secular changes. 


\section{Table 4}

\section{OBC Adoption and Asset Ownership}

$$
\text { All Short Hauls Medium Hauls Long Hauls }
$$

Dependent Variables: Change in For Hire Carriage Shares, 1987-92, 1992-97

\begin{tabular}{|c|c|c|c|c|}
\hline OBC & $\begin{array}{c}-0.090 \\
(0.024)\end{array}$ & $\begin{array}{l}-0.043 \\
(0.049)\end{array}$ & $\begin{array}{c}-0.103 \\
(0.040)\end{array}$ & $\begin{array}{c}-0.113 \\
(0.040)\end{array}$ \\
\hline EVMS & $\begin{array}{c}0.149 \\
(0.028)\end{array}$ & $\begin{array}{c}0.183 \\
(0.068)\end{array}$ & $\begin{array}{c}0.147 \\
(0.052)\end{array}$ & $\begin{array}{c}0.159 \\
(0.043)\end{array}$ \\
\hline $\mathrm{N}$ & 2773 & 736 & 1019 & 1018 \\
\hline \multicolumn{5}{|c|}{ Dependent Variable: Change in For Hire Carriage Share, 1987-92 } \\
\hline OBC & $\begin{array}{c}-0.043 \\
(0.031)\end{array}$ & $\begin{array}{c}0.226 \\
(0.066)\end{array}$ & $\begin{array}{l}-0.087 \\
(0.052)\end{array}$ & $\begin{array}{c}-0.111 \\
(0.052)\end{array}$ \\
\hline EVMS & $\begin{array}{c}0.048 \\
(0.043)\end{array}$ & $\begin{array}{l}-0.138 \\
(0.124)\end{array}$ & $\begin{array}{l}-0.017 \\
(0.019)\end{array}$ & $\begin{array}{c}0.157 \\
(0.062)\end{array}$ \\
\hline$N$ & 3908 & 1115 & 1405 & 1388 \\
\hline
\end{tabular}

Dependent Variable: Change in For Hire Carriage Share, 1992-97

$\begin{array}{lcccc}\text { OBC } & -\mathbf{0 . 0 8 7} & \mathbf{- 0 . 1 5 2} & \mathbf{- 0 . 1 1 6} & -0.058 \\ & \mathbf{( 0 . 0 2 6 )} & \mathbf{( 0 . 0 5 5 )} & \mathbf{( 0 . 0 4 7 )} & (0.040) \\ \text { EVMS } & & & & \\ & \mathbf{0 . 1 7 1} & \mathbf{0 . 1 2 5} & \mathbf{0 . 1 9 3} & \mathbf{0 . 1 5 7} \\ & \mathbf{( 0 . 0 2 9 )} & \mathbf{( 0 . 0 6 8 )} & \mathbf{( 0 . 0 5 4 )} & \mathbf{( 0 . 0 4 2 )} \\ \mathrm{N} & & & & \\ & 4101 & 1097 & 1531 & 1473\end{array}$

SUR estimates.

Includes all cohorts with positive number of observations in each relevant year.

Cohorts weighted by Census' weighting factors times number of observations.

Specifications include change in trailer density and auto trailer and van dummies as controls.

and allow the coefficient on the auto trailer and van dummy to vary across years to account for secular changes. 


\section{Table 5}

\section{OBC Adoption and Asset Ownership - Interactions}

Multitasking Tests

Dependent Variables: Change in For Hire Carriage Share

$\underline{1987-92-97}$

OBC

EVMS

OBC*(Food or Mixed Cargo)

EVMS*(Food or Mixed Cargo)

$\mathrm{OBC}^{*}$ (Petroleum or Chemicals $)$

EVMS*(Petroleum or Chemicals)

N

$$
\begin{aligned}
& -0.010 \\
& (0.036)
\end{aligned}
$$

$-0.066$

(0.040)

$-0.141$

(0.054)

0.142

(0.062)

$-0.111$

(0.074)

0.156

(0.092)

2773
1987-92

$\underline{1992-97}$

$0.033 \quad 0.009$

$(0.046) \quad(0.034)$

$\begin{array}{ll}-0.002 & \mathbf{0 . 0 8 8}\end{array}$

(0.057) (0.039)

$-0.131 \quad-0.241$

(0.069) (0.060)

$0.065 \quad 0.164$

(0.094) (0.064)

$\begin{array}{ll}-0.091 & -0.184\end{array}$

(0.101) (0.076)

$0.021 \quad 0.166$

(0.171) (0.089)

$3908 \quad 4101$

SUR estimates.

Includes all cohorts with positive number of observations in each relevant year.

Cohorts weighted by Census' weighting factors times number of observations.

Specifications include change in trailer density and auto trailer and van dummies as controls.

and allow the coefficient on the auto trailer and van dummy to vary across years to account for secular changes. 


\section{Table 6}

\section{OBC Adoption and Asset Ownership}

GMM-IV Estimates

Dependent Variables: Change in For Hire Carriage Share, 1987-1992, 1992-1997

\begin{tabular}{lcc} 
OBC & 0.097 & \\
& $(0.351)$ & \\
EVMS & 0.391 & $\mathbf{0 . 5 0 2}$ \\
& $(0.408)$ & $\mathbf{( 0 . 0 9 6 )}$ \\
& & \\
OBC*Mult & -0.421 & $\mathbf{- 0 . 3 5 1}$ \\
& $(0.297)$ & $\mathbf{( 0 . 1 4 6 )}$ \\
EVMS*Mult & 0.098 & 0.020 \\
& $(0.326)$ & $(0.158)$ \\
P-value for Test of OID Restrictions & 0.952 & 0.964 \\
\hline & & \\
\hline & & \\
(OBC+EVMS) & & \\
& $\mathbf{0 . 4 8 8}$ & $\mathbf{0 . 5 0 2}$ \\
(OBC+EVMS)*Mult & $\mathbf{( 0 . 1 0 5 )}$ & $\mathbf{( 0 . 0 9 5 )}$ \\
& $\mathbf{- 0 . 3 2 2}$ & $\mathbf{- 0 . 3 3 0}$ \\
& $\mathbf{( 0 . 1 4 3 )}$ & $\mathbf{( 0 . 1 4 1 )}$
\end{tabular}

Instruments include percent of miles out of base state, number of weeks in use per year, west dummy, New England dummy, and interactions among these.

Includes all cohorts with positive number of observations in each relevant year.

Cohorts weighted by Census' weighting factors times number of observations.

Specifications include change in trailer density and auto trailer and van dummies as controls.

and allow the coefficient on the auto trailer and van dummy to vary across years to account for secular changes. 
Table 7

OBC Diffusion and the Private Carriage Share

\begin{tabular}{lccc} 
& \multicolumn{3}{c}{ True Share } \\
& 1987 & 1992 & 1997 \\
& $50.1 \%$ & $54.6 \%$ & $51.7 \%$ \\
& Estimated Share, Absent OBC Adoption \\
& 1987 & 1992 & 1997 \\
& & & \\
Table 6 (Right Columns) & $50.1 \%$ & $54.2 \%$ & $52.6 \%$ \\
Table 7 (Right Column) & $50.1 \%$ & & $59.7 \%$
\end{tabular}


Table A1

First-Stage Estimates: Adoption Equations

\begin{tabular}{|c|c|c|c|c|}
\hline Dependent Variable: & $\begin{array}{c}\text { TR Adoption } \\
1987-1992 \\
\end{array}$ & $\begin{array}{c}\text { TR Adoption } \\
1992-1997 \\
\end{array}$ & $\begin{array}{c}\text { EVMS Adoption } \\
1987-1992\end{array}$ & $\begin{array}{c}\text { EVMS Adoption } \\
1992-1997\end{array}$ \\
\hline West & $\begin{array}{l}0.039 \\
(0.008)\end{array}$ & $\begin{array}{l}-0.012 \\
(0.012)\end{array}$ & $\begin{array}{c}0.037 \\
(0.009)\end{array}$ & $\begin{array}{c}0.002 \\
(0.015)\end{array}$ \\
\hline New England & $\begin{array}{c}0.015 \\
(0.028)\end{array}$ & $\begin{array}{l}-0.021 \\
(0.038)\end{array}$ & $\begin{array}{l}-0.024 \\
(0.029)\end{array}$ & $\begin{array}{c}0.012 \\
(0.050)\end{array}$ \\
\hline Percent Out of Base State & $\begin{array}{c}0.061 \\
(0.020)\end{array}$ & $\begin{array}{l}-0.023 \\
(0.025)\end{array}$ & $\begin{array}{c}0.127 \\
(0.021)\end{array}$ & $\begin{array}{c}0.091 \\
(0.032)\end{array}$ \\
\hline Weeks in Use & $\begin{array}{c}0.004 \\
(0.002)\end{array}$ & $\begin{array}{l}-0.002 \\
(0.002)\end{array}$ & $\begin{array}{c}0.007 \\
(0.002)\end{array}$ & $\begin{array}{l}-0.001 \\
(0.003)\end{array}$ \\
\hline
\end{tabular}

$N=2773$

All specifications include distance, trailer, and product class dummies and the private carriage share.

Includes all cohorts with positive number of observations in each relevant year.

Cohorts weighted by Census' weighting factors times number of observations. 